\title{
THE DETERMINATION OF GLIADIN IN WHEAT FLOUR BY MEANS OF THE POLARISCOPE. ${ }^{1}$
}

\section{BY HARRY SNYDER.}

Recelved January 9. z904.

WHEAT proteids have been studied by a number of investigators. Ritthausen, ${ }^{2}$ one of the earliest workers, recognized four wheat proteids: ( I) Gliadin, soluble in warm dilute alcohol from which it is precipitated on cooling; (2) mucedin, similar to gliadin, but less soluble in strong alcohol; (3) gluten-casein, insoluble in alcohol, but soluble in a dilute alkali solution; and (4) glutin-fibrin. Osborne and Voorhees ${ }^{3}$ have separated five proteids from wheat: (I) An albumin (leucosin) soluble in water; (2) a proteose body; (3) a globulin (edestin) soluble in a dilute salt solution; (4) and (5) two insoluble proteids, gliadin and glutenin. Gliadin is soluble in a dilute alcohol solution and glutenin in a dilute alkali solution.

From 85 to go per cent. of the total proteids of wheat flour are in the form of gliadin and glutenin. In most flours gliadin predominates and constitutes from 55 to 70 per cent. of the total proteid matter. The total protein in wheat flour can be accurately determined by the factor $\mathrm{N} \times 5.70$, in which $\mathrm{N}$ represents the per cent. of total nitrogen as determined by the Kjeldahl process. The amount of non-proteid nitrogen in sound wheat flour is so small that for practical purposes it can be disregarded.

The gliadin can be determined by extracting a weighed amount of flour with dilute alcohol. I have found the following method, based largely upon the work of Osborne and Voorhees, to give satisfactory results. ${ }^{4}$ Five grams of flour are weighed into a flask and $250 \mathrm{cc}$. of 70 per cent. alcohol added; the flask is shaken at half-hour intervals for three hours. After twelve to eighteen hours the alcohol is filtered off, and to Ioo cc. of the filtrate in a $\mathrm{Kjeldahl}$ digestion flask are added about $3 \mathrm{cc}$. of sulphuric acid. The flask is placed in a water-bath and the alcohol evaporated.

\footnotetext{
1 Read at the St. Louis meeting of the American Chemical Society.

2 "Die Elweisskorper der Getreidearten, Hulsenfruchte und Oelsamen," Bonn, 1872. (Contains references to his earlier publications.)

${ }^{8} \mathrm{Am}$. Chem. J., I5, 392 (1893).

" "Proteids of Wheat Flour," Minnesota Expt. Sta. Bull. No. 63, p. 520.
} 
The remainder of the acid is then added and the determination of the nitrogen completed in the tisual way.

While this method gives accurate results, it is not applicable to the technical work of flour testing because too much labor, expense, and time are involved in the various operations. Since the proteids have well-defined optical properties, equally as much as have the sugars, methods based upon the use of the polariscope appear to offer a possible solution to the problem of determining the gliadin content of wheat flour without sacrificing accuracy, and at the same time securing a more rapid and inexpensive method.

The determination of the specific rotary power of gliadin, as reported by $\mathrm{Kjeldahl,}{ }^{1}$ shows that it is highly laevorotary;

$$
[\alpha]_{0}=-92 \text {. }
$$

This figure has recently been confirmed by Osborne, who abtained values for two determinations of -9 I.9 to -92.55 , respectively.

Since most laboratories are provided with polariscopes reading in percentages of sugar instead of degrees of circular polarization, it was deemed advisable to use such an amount of flour that percentages on the sugar scale could easily be transposed to percentages of gliadin nitrogen.

After a number of preliminary trials it was found that 1.5 .07 grams of flour yielded an extract with IOO cc. of 70 per cent. alcohol that would show a polarization of from -4 to -7 on the sugar scale, depending upon the gliadin content of the flour used. It was also found that the polariscope reading multiplied by 0.2 gave figures corresponding approximately with the results obtained for the gliadin nitrogen by the method describec?

In flour, the chief optically active substance is gliadin. The amount of sucrose and invert sugars in wheat flour, according to Krug and Wiley, ${ }^{2}$ does not exceed 0.30 per cent. The amount of non-gliadin proteids soluble in alcohol is small, and not sufficient to affect the polariscope reading to more than a few hundretdths of a per cent. In fact, the combined alcohol-soluble carbohydrates and non-gliadin proteids of the alcoholic solution affect the polarization to only a slight extent. In a number of

1 Bredermann's Centralbiat für agricultur Chemie, 25, 197 (1896).

2 U. S. Dept. of Agr., Bureau of Chem., Bull. 13, Pt. 8. 
cases where the gliadin proteid was precipitated, the non-gliadin rotary bodies showed a reading of less than 0.20 per cent. on the sugar scale, or 0.04 per cent. on the gliadin nitrogen scale. In case extreme accuracy is desired, the gliadin can be precipitated perfectly by mercuric nitrate, and corrections made for non-gliadin rotary bodies. Ordinarily, however, this is not necessary any more than are corrections for raffinose and dextrose in the testing of sugar-beets.

Results obtained with the polariscope compare favorably with those obtained in the way described, from the nitrogen content of the solution. In the following table a few comparative results are given:

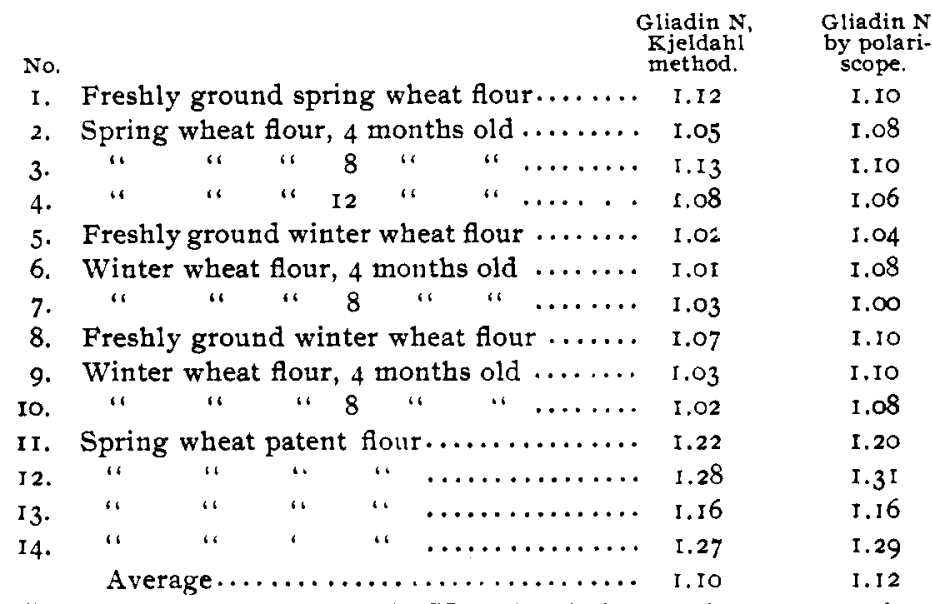

(Credit is due Mr. Ralph Hoagland for assistance rendered in the above analytical work.)

The average gliadin content of the fourteen samples as determined from the analysis of the alcoholic solution was I.IO per cent, and as determined by the polariscope, I.I2. Reducing the average polariscope reading of -5.6 to degrees of circular polarization and substituting the values in the formula

$$
(\alpha)_{\mathrm{D}}=\frac{-\alpha}{p l}
$$

(in which $\alpha$ represents the reading observed, $p$ the weight in grams of gliadin in I cc., and $l$ the length of the tube in decimeters) would give a specific rotary power of about -90 , approximately the specific rotary power of gliadin. 
Briefiy clescribed, the method proposed for the determination of gliadin by the polariscope is as follows: Weigh 15.97 grams of flour into a flask and add roo cc. of 70 per cent. alcohol. Shake the flask moderately at intervals of a half hour for two on three hours. Leave the alcohol in contact with the hour for from twelve to eighteen hours, at a temperature of about $20^{\circ} \mathrm{C}$. Filter the alcoholic solution and polarize, using a $220 \mathrm{~mm}$. tube. Multiply the reading on the sugh scale !y 0.2 . Which gives approximately the per cent. of gliadin nitrogen.

The time of extraction with alcohol can be lessened by the use of a shaking machine and then clarifying the solution by centrifugal action. Excessive shaking is to be avoided, otherwise cloudy filtrates are obtained which cannot be polarized. Some flours, particularly soft wheat flours, frequently sive cloudy filtrates. If the alcoholic solutions are kept too lons: they becons? cloudy and cannot be polarized.

The interpretation of results, particularly as to the amount of gliadin which a sample of flour shall contain for good breaclmaking purposes, is a separate feature of the problem of testing wheat and flour for commercial purposes. As yet, only a limited number of gliadin determinations are available, and only tentative standards are possible. In general, it can be said that flour of good quality should contain I 2 per cent. of total proteids $(N \times 6.25)$, or about II per cent. protem ( $N \times 5.7)$, and that from 55 to 65 per cent. should be in the form of gliadin. It is believed that the method as here proposed of determining the gliadin content of flour by means of the polariscope will be found both rapid and accurate, and particularly applicable where large numbers of determinations are to be made.

TNIVERSITY OF MINNESOTA,

MINNEAPOLIS, MINN.

\section{THE HYDROLYSIS OF MALTOSE AND OF DEXTRIN BY DILUTE ACIDS AND THE DETERIINATION OF STARCH.}

By William a. Noyes, Gilbert Cranford, Charles H. JUMPER, Fdiak L. Flory, AND ROBERT B. AR NOLD.1

Receiver December 10, 1903 .

The method of determining starch in common use consists in converting the starch into a mixture of maltose and dextrin by

1 The work here described formed the basis for theses which were presented for the degree of Bachelor of Science at the Rose Polytechnic Institute by Mr. Crawford in Igor, by Messrs. Jumper and Flory in 1902, and by Mr. Arnold in I903. 